\title{
BMJ Open Public perceptions of cancer: a qualitative study of the balance of positive and negative beliefs
}

\author{
Kathryn A Robb, ${ }^{1}$ Alice E Simon, ${ }^{2}$ Anne Miles, ${ }^{3}$ Jane Wardle ${ }^{2}$
}

To cite: Robb KA, Simon AE, Miles A, et al. Public perceptions of cancer: a qualitative study of the balance of positive and negative beliefs. BMJ Open 2014:4:e005434.

doi:10.1136/bmjopen-2014005434

- Prepublication history for this paper is available online. To view these files please visit the journal online (http://dx.doi.org/10.1136/ bmjopen-2014-005434)

Received 8 April 2014 Revised 20 June 2014 Accepted 23 June 2014

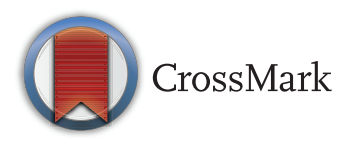

${ }^{1}$ General Practice and Primary Care, Institute of Health and Wellbeing, University of Glasgow, Glasgow, UK

${ }^{2}$ Health Behaviour Research Centre, UCL Department of Epidemiology and Public Health, London, UK ${ }^{3}$ Department of Psychological Sciences, Birkbeck, University of London, London, UK

Correspondence to Dr Kathryn Robb; Katie.Robb@glasgow.ac.uk

\section{ABSTRACT}

Objectives: Cancer's insidious onset and potentially devastating outcomes have made it one of the most feared diseases of the 20th century. However, advances in early diagnosis and treatment mean that death rates are declining, and there are more than 30 million cancer survivors worldwide. This might be expected to result in more sanguine attitudes to the disease. The present study used a qualitative methodology to provide an indepth exploration of attitudes to cancer and describes the balance of negative and positive perspectives.

Design: A qualitative study using semistructured interviews with thematic analysis.

Setting: A university in London, UK.

Participants: 30 participants (23-73 years), never themselves diagnosed with cancer.

Results: Accounts of cancer consistently incorporated negative and positive views. In almost all respondents, the first response identified fear, trauma or death. However, this was followed-sometimes within the same sentence - by acknowledgement that improvements in treatment mean that many patients can survive cancer and may even resume a normal life. Some respondents spontaneously reflected on the contradictions, describing their first response as a 'gut feeling' and the second as a more rational appraisal-albeit one they struggled to believe. Others switched perspective without apparent awareness.

Conclusions: People appear to be 'in two minds' about cancer. A rapid, intuitive sense of dread and imminent death coexists with a deliberative, rational recognition that cancer can be a manageable, or even curable, disease. Recognising cancer's public image could help in the design of effective cancer control messages.

\section{BACKGROUND}

Cancer has long been one of the most feared diseases; widely regarded as synonymous with a death sentence. Even the word 'cancer' can evoke an almost visceral response of dread resulting in euphemisms like the 'Big C'. ${ }^{1-7}$ Used as a metaphor, 'cancer' denotes an insidious process that destroys from within (eg, 'the cancer at the heart of the organisation'). Several qualitative studies have noted

\section{Strengths and limitations of this study}

- The use of a qualitative methodology allowed us to establish the existence of contradictory beliefs within an individual, the subtlety of which may be missed using quantitative methods.

- The study found that despite recognition of improvements in outcomes, visceral fear of the disease is ubiquitous and people have to struggle to control it.

- The findings are interpreted within the Dual Process Theory of human information processing.

- A better understanding of the contradictory public views of cancer could help to improve cancer control communications.

- A limitation was that participants were asked about cancer in general rather than specific types of cancer, and so participants tended to speak about cancer as if it were one disease. Future research could usefully explore whether people also hold positive and negative beliefs about site-specific cancers.

the entrenched nature of cancer fear, especially among ethnic minority communities in the USA. ${ }^{89}$ One of the relatively few quantitative studies also showed that people perceive cancer to be one of the most painful, least understood and deadliest of diseases. ${ }^{10}$ Using the Burns' Cancer Belief Scale, ${ }^{11}$ which asks people to choose between opposing descriptive terms (eg, death vs cure), high levels of cancer fear are observed, even among oncology professionals. ${ }^{12}$

In contrast with its dismal public image, epidemiological analyses show steady improvements in cancer survival. The 5-year survival rate for breast cancer in England and Wales has risen from $52 \%$ in the early 1970 s to $85 \%$ currently, while in the USA it has gone up from $75 \%$ in the mid-1970s to $90 \% .{ }^{13}{ }^{14}$ The 5 -year survival for colorectal cancer has risen from $22 \%$ in the early 1970 s to $55 \%$ in England and Wales, and in the USA from $51 \%$ in the mid-1970s to $65 \% .{ }^{14}{ }^{15}$ Worldwide, there are now estimated to be around 30 million 
cancer survivors, with almost 14 million in the USA alone, living proof of life after cancer.

Some recent surveys find evidence for an increasingly positive public perspective. ${ }^{6} 1617$ In the US Health Information National Trends Survey, $90 \%$ of respondents agreed that 'Getting checked regularly for colon cancer increases the chances of finding cancer when it's easy to treat'. ${ }^{18}$ Similar enthusiasm for early presentation has been identified in the UK. ${ }^{19}$ A recent study of older adults in Canada, Australia, Scandinavia and the UK found that $90 \%$ of respondents agreed with the statement 'Cancer can often be cured' ${ }^{20}$ However, all these studies used a methodology in which respondents were presented with positively framed statements with which they were asked to agree or disagree, and this could inflate the evidence for a positive perspective.

Do the more positive attitudes towards cancer seen in these surveys reflect a much more positive perspective, or are we ambivalent, with intellectually driven hope running alongside, rather than displacing, viscerally driven fear? A recent Israeli study noted fear and hope in a community sample, but the method of analysis contrasted subgroups of the population and did not investigate concurrent endorsement of both views. ${ }^{21}$

The present study used a qualitative methodology to explore public perceptions of cancer and describes the balance of positive and negative beliefs about cancer that emerged.

\section{METHODS}

\section{Participants}

Men and women $(\mathrm{n}=67)$ who had previously taken part in population-based research on cancer prevention and early detection and agreed to be contacted about future research were invited to represent men and women and span the age range. Individuals known to have a cancer diagnosis were excluded because we were interested in attitudes to cancer among those who had not personally experienced a cancer diagnosis. Potential participants were invited by mail to take part in a study about 'how people think about cancer'. Interested participants were asked to contact the research team by mail (using a freepost address), email or telephone to get further information or to arrange a convenient interview time. Of the 67 people invited, 30 agreed to be interviewed and are described in this analysis. Informed consent was obtained before each interview.

\section{Procedure}

Individual face-to-face interviews were conducted in a university office and lasted 30-60 min between late 2007 and early 2008. The interviews were semistructured and followed a topic guide that ranged across general views, personal experiences and attitudes towards treatments and outcomes. Interviews were transcribed verbatim and checked for accuracy by two of the researchers (AM and AES).

\section{Data analysis}

An inductive thematic analysis was used to identify and analyse themes in the data. ${ }^{22}$ The transcripts were read by two of the authors (AES and KAR) who discussed the transcripts and agreed on a coding frame to organise the data and permit analysis within and between transcripts. The analysis described in the current paper focuses on: attitudes to cancer in general, patients with cancer and cancer treatment. Data were analysed by AES and KAR with the assistance of the software package Atlas.ti.

\section{RESULTS}

The demographic characteristics of the 30 participants interviewed are shown in table 1 . The average age was 54 years (range 23-73); there were more women (63\%) than men $(37 \%)$ and almost half were married or cohabiting (47\%). Approximately a third had a family income below $£ 30000$, and a third over $£ 60000$. The majority $(93 \%)$ were Caucasian; reflecting the UK population. ${ }^{23}$ Most participants $(83 \%)$ had experience of cancer among family or friends, but by design did not have personal experience of cancer.

\section{Attitudes to cancer}

In almost all the interviews (26/30), participants associated a cancer diagnosis-or even the word cancerwith death and dread. This was the impulsive response in 19 interviews: "The first picture I have about cancer is death" (P1, F, 47y); "Fear and confusion ... generally it ends in death, catastrophe." (P12, F, 68y); "Scared, death, feeling that you can't control it, it's out of your control." (P11, F, 55y); "Distressing, causes pain, death, anxiety." (P22, F, 54y). The association between cancer

Table 1 Demographic characteristics of the 30 participants

\begin{tabular}{lc}
\hline Characteristic & \\
\hline Age (1 missing) mean years (range) & $54.4(23-73)$ \\
Gender $\mathrm{n}(\%)$ & $11(36.7)$ \\
$\quad$ Male & $19(63.3)$ \\
$\quad$ Female & \\
Ethnicity $\mathrm{n}(\%)$ & $28(93.3)$ \\
$\quad$ Caucasian & $1(3.3)$ \\
African-American & $1(3.3)$ \\
$\quad$ Indian & $14(46.7)$ \\
Marital status $\mathrm{n}(\%)$ & $16(53.3)$ \\
$\quad$ Married/living with partner & \\
$\quad$ Not married & $8(26.6)$ \\
Annual family income (1 missing) $\mathrm{n}(\%)$ & $11(36.6)$ \\
$\quad$ Up to £29 999 & $10(33.3)$ \\
£30 000-£59 999 & \\
$\quad$ More than £60 000 & \\
Experience of cancer among family & \\
and friends (2 missing) $\mathrm{n}(\%)$ & $3(83.3)$ \\
$\quad$ Yes & \\
No &
\end{tabular}


and death was reported more by women $(15 / 19)$ than men $(4 / 11)$, but did not appear to differ by age or by experience of cancer among family and friends.

For a further seven participants, powerfully negative images-but not death as such-constituted the intuitive response: "It [cancer] is quite vindictive ... certainly some will to spread and reproduce and take over, if not the world, then your body" (P14, M, 58y); "Ugly and unsightly ... something that is to be feared ... it ruins your health, it ruins you financially if you do not have adequate insurance. I think it's more like the devil." (P33, F, 25y). Four of the 30 participants did not report a personal fear of cancer or their emotional reaction to it and instead discussed it in a more matter-of-fact manner: "It's just another disease." (P5, M, 63y).

In all the interviews associating cancer with death and dread $(26 / 30)$, the negative statements were followed by a more hopeful view either immediately $(10 / 26)$ or in another part of the interview (16/26): "I see it as a killer, although I'm heartened by the fact that the rate of cure is increasing." (P6, M, 70y); "The first thing you think of is: 'oh, they've had it.' Then you remember that the medical profession say that if it's caught early enough then it's better, and of course it depends where it is and what sort of cancer." (P24, M, 60y); "It's one of the dreaded diseases where you think if I get it 'that's it', when the reality is a lot of the time you get a lump and it's not cancer or it's curable." (P17, F, 54y). In each case, the immediate association was negative, but improvements in early detection and treatment were then acknowledged and recognised to be contradictory to the negative perspective.

The contradiction between negative and positive perspectives was often acknowledged. As one participant said: "I mean I can think of positive things, but, but if you had just said the word cancer to me, negative things would come to my mind to start with." (P22, F, 54y). Another talked about his contradictory thinking as something he could not control: "I amend my thinking to some extent, but my basic image I grew up with is cancer: dead! It's hard to eliminate." (P7, M, 72y). Another participant discussed a similar struggle: "This bond between cancer and death. Cancer and life, you can go on living, there are still important things you can do. But of course because I do think it [the bond between cancer and death] is there, very strongly ... it certainly is for me without wanting it to be necessarily. It's just there. So if there is some way of attacking that bond." (P12, F, 68y). She had been a nurse and acknowledged that early diagnosis was "enormously helpful", and knew people diagnosed with cancer who "had amazing lives and recovered". But even with experience of positive outcomes, and an expressed desire not to hold the association with death, it was still "just there".

The same dual perspective emerged in discussions of risk factors or symptoms: "I am, like most people, actually frightened of it. So I mean in a way I feel a lot of people would, I tend to dodge thinking about it. But I already take into account things like diet, not smoking, not drinking too much, that kind of thing, keeping my weight down, exercising, and .... what to look out for. Another thing would be overcoming my fear of seeing a doctor if I did feel a lump anywhere. I would be terrified I mean, sitting in the waiting room trembling I think." (P34, M, 68y). The stereotype of a patient with cancer as frail and emaciated permeated many of the interviews: "They look haggard, but not romantically haggard. They look aged and skeletal and ... also pretty haunted" (P20, F, age missing). One participant described the figure in Edvard Munch's 'The Scream' as a "cancerlooking person ... a drawn face. Oh, I've got this, I've got cancer." (P7, M, 72y). However, again, the negative stereotype was often contrasted immediately with a more positive image: "I guess the image [is] of somebody very thin and looking very unwell and not very active. There is that side of it, but I also have kind of positive images of people that are absolutely fine actually who are living with cancer and getting on with their life and who aren't terminally ill." (P29, F, 42y). This woman had also described a patient with cancer as "a near-death sort of person" which she then contrasted with the "other side" of cancer, in which the patient is not visibly ill. Another woman also described "two sides" to the patient image, contrasting a view of them looking "horrible" or else "terribly brave" with appreciation that many others just carry on with normal activities: "I think the idea is that you get cancer and you know either you end up dead or looking really horrible or you're sort of terribly brave and battle on like Kylie [Minogue, singer]. But the idea that there are millions of people out there who just get on with their day-to-day, and just carry on with their lives and may or may not survive ... doesn't fit into these pictures at all." (P3, F, 40y). This quote suggests that her default response is negative, but she knows this is not the reality for millions of people diagnosed with cancer, and acknowledges that these two views "don't fit".

Cancer treatments were almost uniformly seen as bad, with P27 giving a typical response: "I think of people with no hair. And I think of the horrors of chemotherapy." (P27, M, 67y). P8 also spoke about cancer treatments being almost as bad as the cancer itself: "You've got this awful thing in your body and you've got treatment as well, which is almost as bad as, well it is killing you as fast as the cancer, isn't it?" (P8, F, 58y). However, later in the interview, she commented that improvements in treatment are not generally acknowledged by the public: "The message is not getting across that the treatment, that is, chemotherapy and radiotherapy, is not quite so dreadful as it perhaps once was in terms of the side effects." Similarly, P18, who had described cancer as: "Fear! I've got more used to it, but it is a horrible word when you are first told that somebody is in that position." (P18, M, 62y), explained that the fear was because, "There isn't a cure and the treatment can be pretty horrible." But later in the interview, he said "I 
think most forms are curable to a degree." So to him, cancer is incurable and curable.

\section{DISCUSSION}

The accounts of cancer that emerged from these interviews show that people continue to be profoundly fearful of the disease, with most seeing it as near synonymous with death, just as has been described by many authors over the past 35 years. ${ }^{1-7}$ However, at the same time, our respondents acknowledged improving outcomes. In 26 of 30 interviews, fear and more positive beliefs were mentioned almost equally in people's responses. They were also described almost simultaneously within the same sentence by some participants $(10 / 30)$. Recognition of the contradictory perspectives varied; some people seemed unaware, while others reflected spontaneously on the inconsistency, often noting the difficulty in reconciling the two views.

One strength of our study was the use of a qualitative methodology, which allowed us to establish the existence of contradictory beliefs within an individual, the subtlety of which may be missed using quantitative methods. This method also has limitations. As is typical of qualitative research, the sample size was small. Participants were drawn from people who had taken part in previous research and agreed to be contacted again, and so may not be representative of those unwilling to participate in research. The participants in this study also knew that it was about cancer and that the interviewer was a cancer researcher, thereby potentially priming a more positive, scientific perspective. Interviews that disguised the focus, for example, by asking about a range of life-threatening events including cancer, might be difficult to achieve but could reveal an even more negative view. Participants were asked about cancer in general rather than specific types of cancer, and so they tended to speak about cancer as if it were one disease. Future research could usefully explore whether people also hold positive and negative beliefs about site-specific cancers. The majority of participants had higher incomes than the average for the UK; nonetheless, a third had low-to-moderate incomes. The mean age of the sample was 54 years, and while the range was good (23-73 years), it could be considered a relatively 'young' sample. The sample was also predominantly White, reflecting the UK population, but future work could examine beliefs among ethnic minority groups. Participants were not explicitly asked how their beliefs were formed (eg, experiences among family and friends, media, professional roles), but this would be important to address in future work.

The negative views of cancer described by the participants reflect the depiction of cancer not just in studies of public perceptions but also in media analyses. Redmond $^{24}$ noted that media reporting of cancer frequently reinforced the myth that cancer is an automatic death sentence while a content analysis of magazine coverage of cancer in Canada reported an emphasis on fear of cancer. ${ }^{25}$ Negative fatalistic perspectives are problematic to cancer control because those holding more fatalistic views are less likely to participate in cancer screening or engage in cancer protective behaviours such as exercise, not smoking and eating more than five fruits and vegetables each day. ${ }^{26}{ }^{27}$ Therefore, addressing fearful and fatalistic beliefs in cancer communications has the potential to improve cancer control.

Other qualitative work has also reported that people simultaneously endorsed fatalistic statements and beliefs about the potential of health behaviours to prevent a range of diseases (heart disease, lung cancer, diabetes and depression), and suggested that fatalistic statements may serve useful functions of stress relief, uncertainty management, sense making and face saving. ${ }^{28}$ The functional role of negative, fatalistic statements may be more apparent for cancer preventive behaviours than beliefs about cancer survival and treatment. One explanation for people holding contradictory views about survival and treatment could relate to the dual nature of human information processing. ${ }^{29-33}$ Contemporary analyses characterise one processing system as fast, emotional and intuitive (System 1) and the other as slow, deliberative and rational (System 2) ${ }^{29}$ In the cancer context, suffering and death would be System 1 responses, while modern narratives of survival and return to normality would be System 2 responses. Interestingly, in most of the interviews, negative responses were fast, first and strongly emotional. Positive responses were second, slower and much less emotional, consistent with differences in speed of Systems 1 and 2 processes. One possible explanation for the persistence of negative views despite an awareness of the improving outcomes comes from the visual images of cancer. According to the 'availability heuristic', a System 1 response, the ease with which we can conjure up an image acts as an informal guide to the frequency of the event. ${ }^{34}$ Dramatic negative images were often reported in the interviews, suggesting that frightening and tragic cases come easily to mind, while images of people returning quietly to their daily life after successful treatment are not very memorable.

Do these results imply that public perceptions of cancer are evolving from the terror depicted by Susan Sontag in $1978 ?^{1}$ The current picture appeared to show terror and more positive beliefs running more or less in parallel. Individuals who were conscious of the contradiction often explained that they knew intellectually about improving outcomes, but this did not alleviate their deep-seated negative beliefs. Perhaps our views of cancer are in transition. Indeed, in the more recent popular literature, Mukherjee's Emperor of all Maladies describes the continued fear of the disease along with the gains in treatment and survival that have been achieved. ${ }^{35}$ Also, the book by Lochlann Jain discusses the contradictions in how we understand cancer. ${ }^{36}$

If people are in 'two minds' about cancer, it is important to know which perspective influences important 
health actions. Festinger ${ }^{37}$ argues that people are motivated to reduce the dissonance resulting from contradictory beliefs by either altering beliefs or reducing the importance of one of them. When an immediate negative view is challenged by a more balanced, rational analysis, the immediate response may 'win the battle'. ${ }^{32}$ As Loewenstein $e t a l^{88}$ put it: 'Fear causes us to slam on the brakes instead of steering into the skid [which we know to be right response], immobilizes us when we have greatest need for strength, causes sexual dysfunction, insomnia, ulcers, and gives us a dry mouth and the jitters at the very moment when there is the greatest premium on clarity and eloquence' (p.269).

However, the Dual Process Theory also describes System 2 as a 'default interventionist' which can, given time, override the intuitive System 1 response. ${ }^{39}$ As most cancer decisions do not have to be made at high speed, this increases the opportunity for the intuitive response to be over-ruled. People who detect a possible cancer symptom (eg, a breast lump) may have an immediate response of terror, but once they have had time to reflect on the situation, they could draw on an alternative narrative in which medical care is seen as a route to a better outcome. The following quote illustrates the deliberative over-ride of emotional responses for someone who found a possible cancer symptom: "I was extremely scared. But at the same time, you need to take action to survive. You need to know for sure whether it's cancer or not." (ref. 40 p.474).

Addressing emotional perspectives in cancer communications may have some advantages in creating a more positive intuitive response to the disease (eg, I'm looking after my granddaughter today because I saw the doctor in time'). Future research could assess implicit and explicit attitude change following exposure to different types of information, and investigate the conditions that help people 'tune into' their deliberative/rational self. Efforts to shift public perceptions in this way may help to address cancer fear and fatalism.

An understanding of dual processing theory could be useful in relation to decision-making about cancer treatment and interpretation of cancer experiences, and future work could usefully explore this. These results also have implications for monitoring public perceptions of cancer. Measures such as the Burns' Cancer Belief Scale $^{11}$ adopt a forced-choice approach between opposing terms (eg, death vs cure). However, if people hold simultaneous but inconsistent beliefs about cancer, this will obscure the nuances. Another common approach is to present positive, medical science-based statements and then ask people whether they agree; but this may cue a System 2 response which would not have occurred otherwise. Matching negatively framed responses could allow the subtle balance of opposing views to be recognised.

Fear and dread of cancer was ubiquitous in this community sample, but it coexisted with recognition that people can survive and live a normal life after a cancer diagnosis, indicating that people are 'in two minds' about the disease. A better understanding of the nature of our contradictory views of cancer could help to improve cancer control communications.

Acknowledgements The authors are grateful to all the participants and to Claudia Redeker for her assistance with the interviews.

Contributors AM, AES and JW designed the study. AM and AES interviewed the participants. KAR, AES and JW analysed and interpreted the data. KR wrote the first draft of the manuscript. All authors reviewed the manuscript and approved the final version.

Funding This work was supported by Cancer Research UK grants C1418/ A14134 and C9227/A8933.

Competing interests None.

Ethics approval The study was approved by the UCL Research Ethics Committee.

Provenance and peer review Not commissioned; externally peer reviewed.

Data sharing statement Extra data from anonymised transcripts are available by emailing Katie.Robb@glasgow.ac.uk.

Open Access This is an Open Access article distributed in accordance with the Creative Commons Attribution Non Commercial (CC BY-NC 4.0) license, which permits others to distribute, remix, adapt, build upon this work noncommercially, and license their derivative works on different terms, provided the original work is properly cited and the use is non-commercial. See: http:// creativecommons.org/licenses/by-nc/4.0/

\section{REFERENCES}

1. Sontag S. Illness as metaphor. New York: Farrar Straus \& Giroux, 1978.

2. Scanlon K, Harding S, Hunt K, et al. Potential barriers to prevention of cancers and to early cancer detection among Irish people living in Britain: a qualitative study. Ethn Health 2006;11:325-41.

3. Berman SH, Wandersman A. Fear of cancer and knowledge of cancer: a review and proposed relevance to hazardous-waste sites. Soc Sci Med 1990;32:81-90.

4. Helman S. Evolving paradigms and perceptions of cancer. Nat Clin Pract Oncol 2005;2:618-24.

5. Macdonald S, Watt G, Macleod U. In search of the cancer candidate: can lay epidemiology help? Sociol Health IIIn 2012;35:575-91.

6. Livestrong Report. Cancer Stigma and Silence Around the World, 2011. http://www.livestrong.org/pdfs/3-0/LSGlobalResearchReport (accessed May 2014).

7. Cho J, Smith K, Choi EK, et al. Public attitudes toward cancer and cancer patients: a national survey in Korea. Psychooncology 2013;22:605-13.

8. Dein S. Explanatory models of and attitudes towards cancer in different cultures. Lancet Oncol 2004;5:119-24.

9. Peek M, Sayad J, Markwardt R. Fear, fatalism and breast cancer screening in low-income African-American women: the role of clinicians and the health care system. J Gen Intern Med 2008;23:1847-53

10. Katz I, Hass RG, Parisi N, et al. Lay people's and health care personnel's perceptions of cancer, AIDS, cardiac, and diabetic patients. Psychol Rep 1987;60:615-29.

11. Burns N. Selecting a tool for measuring cancer attitudes. In: Frank-Stromborg M, Olsen SJ, eds. Instruments for clinical health research. Sudbury: Jones and Bartlett Publishers, 2004:335-51.

12. Kearney N, Miller M, Paul J, et al. Oncology health care professionals' attitudes to cancer: a professional concern. Ann Oncol 2003;14:57-61.

13. Cancer Research UK. http://www.cancerresearchuk.org/cancer-info/ cancerstats/types/breast/survival/breast-cancer-survivalstatistics\#Trends (accessed May 2014).

14. American Cancer Society. Cancer Facts \& Figures 2013. http://www. cancer.org/acs/groups/content/@epidemiologysurveilance/ documents/document/acspc-036845.pdf. (accessed Apr 2014).

15. Cancer Research UK. http://www.cancerresearchuk.org/cancer-info/ cancerstats/types/bowel/survival/\#trends. (accessed May 2014).

16. PACE A Lilly Oncology Initiative. A six-nation survey of cancer knowledge and attitudes among the general population, patients and caregivers 2012. https://pacenetwork.com/lilly_pace_global_report_ nov_30.pdf. (accessed May 2014). 
17. Keeney S, McKenna H, Fleming $\mathrm{P}$, et al. Attitudes to cancer and cancer prevention: what do people aged 35-54 years think? Eur J Cancer Care (Engl) 2010;19:769-77.

18. Rutten LF, Hesse BW, Moser RP, et al. Public perceptions of cancer prevention, screening, and survival: comparison with state-ofscience-evidence for colon, skin, and lung cancer. J Cancer Educ 2009;24:40-8.

19. Beeken RJ, Simon AE, von Wagner C, et al. Cancer fatalism: deterring early presentation and increasing social inequalities? Cancer Epidemiol Biomarkers Prev 2011;20:2127-31.

20. Forbes LJ, Simon AE, Warburton F, et al. Differences in cancer awareness and beliefs between Australia, Canada, Denmark, Norway, Sweden and the UK (the International Benchmarking Partnership): do they contribute to differences in cancer survival? Br J Cancer 2013;108:292-300.

21. Baron-Epel O, Klin A. Cancer as perceived by a middle-aged Jewish urban population in Israel. Oncol Nurs Forum 2009;36:E326-34.

22. Braun V, Clarke V. Using thematic analysis in psychology. Qual Res Psychol 2006;3:77-101.

23. United Kingdom Census 2001: Focus on ethnicity and identity data. Office for National Statistics. http://www.ons.gov.uk/ons/publications/ re-reference-tables.html?edition=tcm\%3A77-50846 (accessed Apr 2014)

24. Redmond K. Promoting better quality media coverage of cancer Nat Clin Pract Oncol 2007;11:613.

25. Clarke JN, Everest MM. Cancer in the mass print media: fear, uncertainty and the medical model. Soc Sci Med 2006;62:2591-600.

26. Miles A, Rainbow S, von Wagner C. Cancer fatalism and poor self-rated health mediate the association between socioeconomic status and uptake of colorectal cancer screening in England. Cancer Epidemiol Biomarkers Prev 2011;20:2132-40.
27. Niederpeppe J, Levy AG. Fatalistic beliefs about cancer prevention and three prevention behaviors. Cancer Epidemiol Biomarkers Prev 2007;16:998-1003.

28. Keeley B, Wright L, Condit CM. Functions of health fatalism: fatalistic talk as face saving, uncertainty management, stress relief and sense making. Sociol Health IIIn 2009;31:734-47.

29. Kahneman D. Thinking, Fast and Slow. London: Allen Lane, 2011.

30. Wilson TD, Lindsey S, Schooler TY. A model of dual attitudes. Psychol Rev 2000;107:101-26.

31. Strack F, Deutsch R. Reflective and impulsive determinants of social behaviour. Pers Soc Psychol 2004;8:220-47.

32. Epstein S. An integration of the cognitive and the psychodynamic unconscious. Amer Psychol 1994;49:709-24.

33. Cameron LD, Leventhal $\mathrm{H}$, eds. The self-regulation of health and illness behavior. New York: Routledge, 2003.

34. Tversky A, Kahneman D. Judgment under uncertainty: heuristics and biases. Science 1974;185:1124-31.

35. Mukherjee S. The emperor of all maladies. London: Fourth Estate, 2011.

36. Jain SL. Malignant: How cancer becomes us. London: University of California Press, 2013.

37. Festinger L. A theory of cognitive dissonance. Stanford, CA: Stanford University Press, 1957.

38. Loewenstein G, Weber EU, Hsee CK, et al. Risk as feelings. Psychol Bull 2001;127:267-86.

39. Evans J, St BT, Stanovich KE. Theory and metatheory in the study of dual processing: reply to comments. Perspect Psychol Sci 2013;8:263-71.

40. de Nooijer J, Lechner L, De Vries H. Help-seeking behaviour for cancer symptoms: perceptions of patients and general practitioners. Psychooncology 2001;10:469-78. 